\title{
The translation of $o h$ in a corpus of dubbed sitcoms
}

\author{
Anna Matamala \\ Universitat Autònoma de Barcelona \\ 08193 Bellaterra (Barcelona). Spain \\ annamaria.matamala@uab.cat
}

\begin{abstract}
This article aims to study the functions of the interjection $o h$ in a corpus of English sitcoms and their translation in the Catalan dubbed version. After defining the functions and patterns of this unit in the original English corpus and attempting a classification, the translation strategies used are analysed taking into account different factors such as frequency and specific constraints inherent to this type of audiovisual translation (i.e. lip synchronisation). This article will explore whether $o h$ is translated by interjections, omitted or translated by non-interjective structures. Attention is also paid to combinations in which this unit appears.
\end{abstract}

Key-words: interjections, audiovisual translation, orality, oh, Catalan, English.

\section{Table of Contents}

\section{0 . Introduction}

1. The interjection $o h$ in the literature

2. Defining interjections and the corpus of study
4. Translation strategies

5. Conclusions

References

3. Corpus analysis: oh, its function, position and structure

\section{Introduction}

Conversations in English are full of units such as $o h$, which due to their elusive nature are sometimes denied their own identity and rather neglected in the literature. Although apparently insignificant, these units add semanticopragmatic meaning to discourse. However, their systematisation is hindered by their often ambiguous and polysemic nature. This article aims to study the functions and patterns of the English interjection $o h$ in an audiovisual corpus of English sitcoms as well as their translation in the Catalan dubbed version.

First, a general overview of the bibliography on the English interjection oh will be presented $(\S 1)$ and the category "interjection" as well as the corpus of study will be described (\$2). Then, the various functions and contexts of $o h$ in our corpus will be systematised ( $\$ 3)$ and an analysis of the strategies implemented in the translation of this unit into Catalan will be offered $(\S 4)$. 


\section{The interjection $o h$ in the literature}

Oh has been analysed in the literature by various authors, although not always under the same heading. James (1973) undertakes the syntactic and semantic analysis of a few interjections (oh, ah, uh, say and well) in the framework of generative semantics and identifies two main types of usages of $o h$, which she summarises in figure 1 (James 1973: 38).

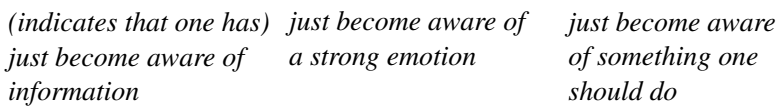

(can) indicate

pleasure/significance

Need not indicate

pleasure/significance

\begin{tabular}{|l|l|l|}
\hline $\mathrm{Oh}_{1} \mathrm{ah}$ & $\mathrm{Oh}_{1} \mathrm{Ah}$ & $\mathrm{Oh}_{1} \mathrm{Ah}$ \\
\hline $\mathrm{Oh}_{1}$ & $\mathrm{Oh}_{1}$ & $\mathrm{Oh}_{1}$ \\
\hline
\end{tabular}

indicates "casualness"

$\mathrm{Oh}\left(\mathrm{Oh}_{2}\right)$

indicates a decision

process

$\mathrm{Oh}_{2}$

Figure 1. Usages of $o h$ according to James (1973).

Thus, according to James, $o h_{1}$ indicates that one has become aware of something in general, of something one should do, or even of a strong emotion, either with an added element of pleasure or not. When it indicates pleasure, $a h$ is also used as an alternative to this $o h$. On the other hand, $o h_{2}$ is used to indicate awareness in all the three previous contexts, transmitting casualness or a decision process at the same time. Later on, James improves this initial classification by adding that $o h_{1}$ can indicate any emotion (or none), can be used before echoes and stands easily by itself.

Likewise, Heritage (1984: 229) believes that this unit "is used to propose that its producer has undergone some kind of change in his or her locally current state of knowledge, information, orientation or awareness". A year later, Schourup (1985) analyses common discourse particles in English conversation and, although not central to his study, some remarks are also made regarding $o h$, which is considered an evincive ${ }^{1}$ often encountered in turn-initial and quotation-initial positions

1. Schourup (1985: 18) defines an evincive as "a linguistic item that indicates that at the moment at which it is said the speaker is engaged in, or has just then been engaged in, thinking; the evincive item indicates that this thinking is now occurring or has just now occurred but does not completely specify its content". 
that expresses that some thought has occurred despite not specifying the nature of that thought. Adapting James' differentiation, Schourup also proposes to distinguish between $o h_{1}$-indicating that the speaker has become aware of something and wishes to show it- $o h_{2}$ - evidencing that the speaker has paused to make a decision or choice between alternatives - and $o h_{3}$ —included by James in the second group but given their own identity by Schourup, being more casual and evincing introspection in a similar way to well.

Tshomba (1986) adopts speech act theory to analyse the interjective forms oh, $a h$ and well, and considers that $o h$ can express a deliberate hesitation, can show that the speaker has just remembered something and can even denote surprise or compassion. In isolation oh usually stands for a proposition and is considered to be a reaction and, at the same time, a response to a fact or situation. Stress, intonation, facial expressions and the relationship between the speaker and the hearer will also shape different values of $o h$, as it is always context-bound.

In 1987, Schiffrin published her seminal book on discourse markers and devoted a whole chapter to the analysis of $o h$ as a marker of information management. In spite of traditionally being viewed as an exclamation or an interjection expressing strong emotional states when used alone - a view recurrently found in traditional grammars-, Schiffrin considers its additional use in initiating utterances and focuses on its information management tasks, especially when used in repairs (repair initiation, repair completion and repairs achieved through clarification sequences), in question/answer/acknowledgement sequences, as a recognition display, as information receipt or as a marker of shifts in speaker orientation.

Fischer (2000) also distinguishes between various functions of the English interjection $o h$ : as a signal of perception and understanding of the previous speaker's utterance (usually turn-initially and followed by a statement directly related to the previous utterance), and as a back-channel signal — usually in combination with yes or yeah. Examples are also presented where oh introduces an evaluation or assessment, and where it is used turn-medially before quoted speech.

Finally, highlighting the large number of pragmatic values discourse particles can be associated with, Aijmer (2002) presents a linguistic description of a selection of these units which includes $o h$, considered an interjection which has developed via a process of grammaticalisation into a discourse particle. $O h$ is described as a response (or reception) marker used in discourse regulation (coming to a realisation, clarification sequences, self-repair, assertion and emphasis, reaction or objection) —a view shared by Jucker and Smith (1998: 174) — and also as a unit used to index affect and emotion (intensification, upgrading, downtoning), presenting respectively backwards-looking and forwards-looking functions in discourse. Due to the lack of propositional meaning and to the fact that its varied discourse functions depend on context (collocations, position, prosody, text type and position in the text), defining its core meaning presents a challenge. Aijmer considers that this core meaning derives from its origin as an interjection meaning surprise or unexpectedness.

No monographic studies on the interjection oh exist in Catalan and references to their functions are made very rarely in grammars and other studies. Such refer- 
ences are made in Torres Vilatarsana (1999) — who considers it to convey an expressive function (surprise and complaint, prototypically) — and, especially, in Matamala (2005a: 336-340), whose conclusions will be partly portrayed in section 3 .

\section{Defining interjections and the corpus of study}

Oh has traditionally been defined as an interjection, albeit other labels such as discourse particle or discourse marker have been attributed to this unit once its function in discourse has been recognised. In this article I will consider $o h$ to be an interjection, not just in the traditional sense of a unit of exclamatory nature only transmitting expressive values but in the sense proposed by Cuenca (2000, 2002a): consequently, adopting a prototype approach to categories, interjections are considered a context-sensitive peripheral class of the category "sentence" that typically encode pragmatic meanings and can sometimes present anomalous phonetic patterns. Interjections tend to be morphologically invariable and constitute a semi-open class in which primary interjections (oh, ouch, hey, etc.) and secondary interjections (sorry, Good Lord, damn, etc.) can be distinguished on the basis of their formal and ethymological characteristics: whereas primary interjections are simple and fixed forms with an exclusively interjective value, secondary interjections are units belonging to other word classes that have become interjections by means of a grammaticalization process. In reference to their meaning, the linguistic functions of Jakobson, with the exception of the poetic function, are used to differentiate referential, expressive, conative, phatic and metalinguistic interjections.

Hence, interjections are not simply units of an expressive nature but also units that can be used as discourse markers, since the term "interjection" refers to a grammatical category, whereas "discourse marker" (or "discourse particle") refers to a functional category. In this broad context, $o h$ is considered a prototypical primary interjection whose meaning goes beyond the traditional expressive function and ventures into the realm of discourse, as will be shown in section 3 .

Taking into account this theoretical framework, I will analyse the instances of the interjection $o h$ found in a relevant section of the audiovisual corpus of sitcoms developed by Matamala (2005a), namely the bilingual subcorpus. This subcorpus includes one episode of the British sitcom Coupling, one episode of the American sitcom Working and one episode of the American sitcom Normal, Ohio, both in their original and dubbed version. The subcorpus includes the English transcription of the sitcom aligned with video excerpts, and also aligned with the transcription of the Catalan dubbing and its video excerpts. Although this subcorpus is rather limited in size (approximately 10,000 words in Catalan and 10,000 words in English), it includes 362 interjections in English and 296 interjections in Catalan, of which 53 correspond to the English interjection $o h$. These instances will be analysed bearing in mind two important issues:

a) the limited number of occurrences will only permit the description of tendencies which should be further confirmed in a wider study, and 
b) the corpus corresponds to a genre which imitates oral language but which is not real spontaneous language and which is moreover constrained by the restrictions imposed by dubbing (Matamala 2005b). Nevertheless, some authors have acknowledged the utility of using the dialogues in playwrights or film scripts as typical interactions (Tannen and Lakoff 1994, Fischer 2000: 204).

\section{Corpus analysis: $o h$, its function, position and structure}

The multifunctional nature of this type of units is a recurrent topic in the literature (Bazzanella and Morra 2000, Aijmer 2002) and oh is a prototypically polysemic unit, a typical feature of words with a weak phonological entity easily modifiable by intonation (Matamala 2005a). In this case, the prototypical values of $o h$ are linked to the fact of realising something and to its expressive nature, either positive (admiration, pleasure, surprise, etc.), neutral (calm, etc.) or negative (anger, annoyance, etc.), even though additional layers of meaning can be added.

The expressive nature of $o h$ can be visualized in the following examples. In (1) the audience hears a home porn video of Sally having sex with Patrick and there is no doubt that $o h$ depicts pleasure, the same feeling transmitted by Tim when he is given a massage in (2) and represented graphically with an extended vowel. In all these cases $o h$ is in an utterance-initial position and followed by a vocative in most examples.

(1) Sally: Oh, oh, Patrick. Oh, yes. Oh, baby. (Coupling)

(2) Tim: Ooh, do that again, do that again, do that again. (Working)

With a change of intonation, oh in (3) expresses disappointment because Pamela has prepared a yam soufflé but, unfortunately, her brother has not turned up for dinner, and in (4) it is used to manifest pain when burning herself.

(3) Pamela: I made a yam soufflé. Ooh! It puffed up and everything. (Normal, Ohio)

(4) Pamela: Oh!// My hands! Watch out! (Normal, Ohio)

However, the main value is that which could be called "realisation of something", i.e. becoming aware of something and reacting to it either with no special emotion $(5,6)$ or adding a feeling of surprise $(7)$, moan/complaint (8) or other values such as pity, annoyance or admiration. In (5) Patrick reacts to what Jane has uttered while in (6) Jane reacts to an unexpected situation (finding Patrick surrounded by friends when she wanted to be alone with him). On the other hand, in (7) Butch is delighted because her sister has prepared a pumpkin soup, which he was not expecting, and in (8) the same character is talking to his son after a man has insulted him. 
(5) Jane: I sense absolute terrible tragic loneliness.

Patrick: $O h$, so you came round here for a bit of company? Good decision. I'm pleased you did that. (Coupling)

(6) Patrick: Jane.

Jane: I'm very worried about the size of your loneliness. Oh, you trying to deal with your loneliness by surrounding yourself with friends, huh? (Coupling)

(7) Pamela: No, do... don't you dare fork that.

Butch: Sorry, ma'am. Oooh, pumpkin soup.

Pamela: No, get... get your spoon outta here.

Butch: Well, if I use my tongue it'll burn it. (Normal, Ohio)

(8) Charlie: Didn't you want to kill that guy?

Butch: Yeah. And in the past, I would have.

Charlie: $O h$, don't start about the whole fighting doesn't solve anything. (Normal, Ohio)

Sometimes this function can be combined with a phatic function, being the final meaning equivalent to "yes, of course, I agree", as in (9), or "no, I disagree", as in (10). However, the meaning can also be completely altered by the functional tenor, easily noticeable thanks to intonation and body language: in (11) it is obvious that Sally is not having heaps of fun watching porn videos about her and in (12) Delaney wants to express just the opposite, i.e. that the legal department will not like Matt's idea of establishing a four-day work week.

(9) Pamela: Wasn't this a good idea?

Butch: Oh, the best. (Normal, Ohio)

(10) Pamela: Are you blaming my street for Detroit losing?

Bill: No. I'm just saying you live on an unlucky street. I mean, look at your life! Joan: Oh, Bill, there's no such thing as bad luck. She brought it on herself. (Normal, Ohio)

(11) Jane: Anyway, what are you all doing here and why wasn't I invited, huh? Is it something fun?

Sally: $O h$, heaps of fun. We're watching porn videos about me.

(12) Hal: The legal department wants to talk to you about your idea.

Matt: You think they like it?

Delaney: Oh, I'm sure they love it! That's why they became lawyers. They need to be around love all day long. (Working).

The permeability of $o h$ to various values can be verified when it reinforces an utterance which incites the hearer to do something, generally by means of a vocative or an imperative, establishing at the same time a link between two consecutive sentences (13). 
(13) Steve: Patrick, you don't get to see my girlfriend naked, that's the rules. $O h$, Jeff, tell him the naked rules. (Coupling)

Finally, there is even one instance (14) in which two values clearly overlap: $o h, o h, o h$ is used as an indication that the hearer has become aware of what the speaker has just said, but at the same time works as a representative or onomatopoeic interjection imitating laughter.

(14) Elizabeth: Didn't you hear, honey? Counter-clockwise!

Danny: $O h, o h, o h$, everything smelled so good. I went into vapour lock or something (Normal, Ohio)

Figure 2 summarises the values attributed to various occurrences of $o h$ in our corpus as well as their graphical variants.

\begin{tabular}{|c|c|c|c|c|}
\hline \multirow[b]{2}{*}{ Expressive } & Pleasure & 6 & \multirow[b]{2}{*}{$13.3 \%$} & Oh (4), Ooh (1), Oh, oh (1) \\
\hline & Pain & 1 & & Oh (1) \\
\hline Realisation & +no specific value & 14 & $26.5 \%$ & Oh (13) \\
\hline \multirow[t]{6}{*}{ Realisation } & + disappointment & 1 & \multirow{6}{*}{$34 \%$} & Ooh (1) \\
\hline & +complaint/moan & 5 & & Oh (5) \\
\hline & +surprise & 6 & & Oh (6) \\
\hline & + pity & 1 & & Oh (1) \\
\hline & +admiration & 4 & & Oh, oh, oh (1) \\
\hline & +annoyance & 1 & & Oh (1) \\
\hline Realisation & +repr./imitating laughter & 1 & $1.8 \%$ & Oh, oh, oh (1) \\
\hline \multirow[t]{4}{*}{ Realisation } & +phatic/agreement & 7 & \multirow{2}{*}{$15 \%$} & Oh (6) \\
\hline & +phatic/disagreement & 1 & & Oh (1) \\
\hline & + conative/incite sb to do sth & 5 & $9.4 \%$ & Oh (5) \\
\hline & & 53 & & \\
\hline
\end{tabular}

Figure 2. Values of $o h$. 
As for the analysis of their position and patterns, three different instances can be clearly distinguished: when oh is found isolated -being an intervention on its own (Briz 2001:53) -, when oh is followed by various linguistic units and when $o h$ is followed by other interjections.

\section{a) Oh in an isolated position}

In the whole of our corpus only one isolated instance of this interjection exists: an oh shouted by Pamela after burning herself with a hot plate and reproduced in example (4) above. This tendency was previously detected by Hernanz (2002: 1011), Cuenca (2002a: 3213) and Matamala (2005a: 261), and is explained by the second linguist in terms of lexical information: since interjections are characterised by their semantic imprecision, the speaker feels the need to complement this initial interjection by means of further units with more lexical content.

\section{b) Oh followed by various linguistic units}

Regarding their position, all instances present the interjection $o h$ at the beginning of an utterance. As far as the speaking-turn is concerned, most instances present an oh right at the beginning, although in $15 \%$ of the cases (six occurrences) this interjection is found in the middle of a speaking-turn, maintaining nonetheless its utterance-initial position (15).

(15) Patrick: Biggest come on I've ever had.

Jeff: Oh, you've had more than one come on. Oh, that's brilliant. (Coupling)

Concerning their combination with other units, there is no doubt that the combination of $o h$ plus a sentence is the most frequent one, comprising $47.5 \%$ of the examples, which mainly correspond to the meaning "realisation of something" (see 16). In Matamala (2005a: 259), where a wider selection of interjections were analysed, the structure [primary interjection + sentence] was the second most frequent pattern, after [secondary interjection + sentence], both in English and in Catalan.

(16) Tim: Why is the sky blue, why is the grass always greener on the other side, why can you lead a horse to water and cannot make him...

Matt: $O h$, I follow. I know exactly what you're saying.

Tim: You do?

Matt: Yeah. You're not man enough to make a decision. (Working)

In $12.5 \%$ of instances the structure presents a slight variation and includes a vocative between the interjection and the sentence (17), and $10 \%$ presents only a vocative after $o h(18)$. In $2.5 \%$ of instances this vocative is followed by formulaic units such as "please" or "Happy Thanksgiving" (19).

(17) Jane: You're the only one who hasn't been steved.

Sally: Oh, Jane, Steve's nice but Patrick's enormous. (Coupling) 
(18) Pamela: Okay, fine, I'll yell at you! I worked so hard to make a nice dinner. Butch: Oh, honey... (Normal, Ohio)

(19) Elizabeth: Suppose you want to go too?

Danny: I hear there'll be cranberry sauce.

Butch: $O h$, honey, please.

Elizabeth: Fine. We'll go. (Normal, Ohio)

Other patterns are those of $o h$ plus a sentence-equivalent item (15\%), plus yes or $n o(7.5 \%)$ or even plus yes/no and sentence (5\%), variations illustrated in (20), (21) and (22).

(20) Steve: What was in the cupboard?

Patrick: Sharon, of course.

Jeff: Oh, Sharon Stone! (Coupling)

(21) Patrick: She's mad, isn't she, Jane?

Steve: $O h$, yeah. (Coupling)

(22) Patrick: Full backal's really annoy me, it's like unfinished work

Jeff: $O h$, yeah, but it does leave something to your imagination, though. (Coupling)

c) Oh followed by other interjections

Again, in these cases all interjections are found sentence-initially, even though there is one example which includes them in the middle of a wider speaking-turn. A common pattern is the combination of one or more interjections after $o h$, either isolated $(18.2 \%)$, followed by a sentence $(27.2 \%)$ or followed by a vocative $(18.2 \%)$, as in examples (23), (24) and (25), respectively.

(23) Jeff: The thing about Jane, right?, the thing that you've got to understand. Steve: Oh God!

Jeff: No, this is relevant. (Coupling)

(24) Butch: Oh, darn, I'm out of popcorn. I'll be right back. (Normal, Ohio)

(25) Butch: Okay, I'm home! We can eat! You can all yell "surprise" now. Pamela: Oh, hello, Butch. (Normal, Ohio)

When $o h$ is followed by an interjection - except for those spoken units where oh is duplicated-, it is always a secondary interjection (God, damn, right, sure, thank you, look and hello) and never another primary interjection. In fact, as pointed out by Matamala (2005a: 260), the pattern [primary + secondary interjection] is the most frequent combination of interjections found both in English and Catalan. 
Moreover, in two instances even more than one interjection is found (for example, in "oh, right, thanks").

On the other hand, there are three occurrences in which the interjection repeated is $o h$ itself, either twice or three times, and followed by a sentence ("Oh, oh, oh, everything smelled so good"), a sentence-equivalent structure ("Oh, oh, oh, Britt. Britt Eckland spells naked") or a vocative ("Oh, oh, Patrick”). Figure 3 summarises the patterns related to the interjection $o h$ presented above, with the number of occurrences and the percentage both from a global perspective and within each group.

\begin{tabular}{|c|c|c|c|}
\hline & Occurrences & $\begin{array}{c}\text { Global } \\
\text { percentage }\end{array}$ & $\begin{array}{c}\text { Partial } \\
\text { percentages }\end{array}$ \\
\hline A: isolated & 1 & $1.9 \%$ & $100 \%$ \\
\hline B: followed by other linguistic units & & $76.9 \%$ & \\
\hline+ vocative & 4 & & $10 \%$ \\
\hline+ vocative + formulaic units & 1 & & $2.5 \%$ \\
\hline+ vocative + sentence & 5 & & $12.5 \%$ \\
\hline+ sentence & 19 & & $47.5 \%$ \\
\hline+ sentence-equivalent item & 6 & & $15 \%$ \\
\hline$+y e s / n o$ & 3 & & $7.5 \%$ \\
\hline+ yes/no + sentence & 2 & & $5 \%$ \\
\hline C: combined with other interjections & & $21.2 \%$ & \\
\hline+ interjection $/ \mathrm{s}$ & 2 & & $18.2 \%$ \\
\hline+ interjection $/ \mathrm{s}+$ sentence & 3 & & $27.2 \%$ \\
\hline +interjection + vocative & 2 & & $18.2 \%$ \\
\hline +interjection + yes/no + interjection & 1 & & $9.1 \%$ \\
\hline+ repeated $o h+$ sentence & 1 & & $9.1 \%$ \\
\hline+ repeated $o h+$ sentence-equivalent item & 1 & & $9.1 \%$ \\
\hline+ repeated $o h+$ vocative & 1 & & $9.1 \%$ \\
\hline
\end{tabular}

Figure 3. Patterns of the interjection "oh". 


\section{Translation strategies}

After defining the functions accomplished by this unit in the original English corpus and attempting a classification, the translation strategies used will now be analysed taking into account different factors such as frequency or specific constraints inherent to this type of audiovisual translation. Interjections, as highlighted by Cuenca (2002b: 300), pose "important problems for translation as they are language-specific in form and, mostly, in use: many languages share identical or similar forms or word-formation processes but the conditions of use of the interjections are not the same", which leads to interference and pragmatic errors, an issue dealt with by the linguist in a more recent article (Cuenca 2006).

The analysis will take into account interjections which are isolated or followed by other linguistic units (\$4.1.) -instances A and B in Figure 3- and interjections which are repeated or combined with other interjections $-\mathrm{C}$ in Figure 3(§4.2.). Formal correspondences will be emphasized over functional ones, despite the interest of an in-depth study of both phenomena.

\subsection{Translation strategies in non-combined interjections}

Translation strategies found in this case are as follows:

\section{a) Omission of the interjection}

In $56.1 \%$ of instances the English oh is omitted in the Catalan version: these correspond to interjections expressing pleasure ( 2 instances), realisation of something plus no specific value (4 instances), realisation + complaint/moan ( 2 instances), realisation + surprise ( 5 instances), realisation + admiration ( 1 instance), realisation + annoyance (1 instance), agreement (5 instances) and a conative value ( 3 instances). However, how is this semanticopragmatic content transmitted in the translation? Is it lost? Is this omission due to dubbing constraints? And, most importantly, does it affect the final meaning? Analysing the 23 occurrences, one can conclude that:

- In some instances intonation in Catalan transmits the value of the original interjection, especially when expressing feelings such as surprise or admiration. For instance, in example (15) above, the translation of "Oh, that's brilliant!" is just "Fantàstic!" ('Fantastic') without any previous primary interjection but no meaning is lost.

- Occasionally the translator chooses mechanisms which seem more natural in the Catalan version, such as translating the function of the original interjection by means of another unit: translating $o h$ by sí ('yes'), when the interjection $o h$ has a phatic meaning, or intensifying a sentence by means of the particle pas instead of including an initial primary interjection, as in the following examples.

- Hey, I think it went pretty well tonight, huh?/ Oh, dinner was great> Sí, el sopar era excel-lent ('Yes, dinner was great').

- I can't believe this thing went into overtime. Pamela's gonna kill me./ Oh, we're not that late.> No és pas tan tard ('It is not that late, contrary to what you think.'). 
- Sometimes the value transmitted by the interjection oh is lost due to dubbing constraints. ${ }^{2}$ For example, the unit "oh, heaps of fun" is translated by "Un sac de rialles" ('a sackful of laughter', literally). If the translator had wanted to include an initial $o h$, it would have been difficult to synchronise the translation with the original.

- On the other hand, and still in the realm of dubbing, it is interesting to notice that, even though an $o h$ would have perfectly fitted the lip movements of the actor when translating "Oh, I do" as a response to the question "Who wants to hear a joke" (Normal, Ohio), the translator has decided to duplicate the personal pronoun "jo" ('Me') and translate the previous answer as "Jo, jo!" ('Me, me'), a perfectly synchronised translation which undoubtedly sounds more natural.

- Finally, when various people are talking at the same time and their lips are not visible, actors are given more freedom to improvise and equivalences are not exact. For example, in Coupling, a sex scene from a home porn video is heard without being visible on screen, as shown below:

- Original: "Oh, oh, Patrick. Oh, yes. Oh, baby" and various moans.

- Catalan written version: "(ADLIBS) (OFF) (GESTOS I CRITS) Més! Més! Així! Així! Oh! Així! No paris! Continua! Així, que bé! M’agrada! Per aquí! Per aquí! Ja em ve!" ('More! More! Like this! Like this! Oh! Like this! Don't stop! Keep going! Oh, this is great! I love it! Here! Here! I'm coming!')

- Final broadcast version: "Més! Ah! Ah! Que bé! Que bé! Oh, oh! No paris! M'agrada! Per aquí!" ('More! Oh! Oh! This is great! This is great! Oh, oh! Don't stop! I love it! Here!')

The symbols included by the adaptor indicate to actors that there is unintelligible dialogue in the original which has to be filled in the dubbed version (ADLIBS), that none of the speakers appear on screen (OFF) and that they should add vocal gestures and cries (GESTOS i CRITS), like those suggested after these indications. This freedom explains why the final broadcast version differs from the original and why one of the original oh's is omitted.

In brief, one can conclude that the omission of $o h$ is not generally due to dubbing constraints: there is no doubt that in most cases it would be possible to introduce a Catalan $o h$ where an English $o h$ appears, but the translator - aware of the differences in frequency of this unit in both languages - deliberately decides to eliminate it and compensates it by means of other added elements (additional linguistic units, intonation, etc.) or elements already present in the audiovisual product such as the body language of the characters (facial expressions, etc.).

2. In Matamala (forthcoming) I describe the dubbing process and analyse in detail the changes original written translations undergo until they are broadcast. In Matamala (2005a) there is also a detailed description of these processes and it is shown, for example, how certain interjections that find their way in the final broadcast version were different in the original written translation. In this article I only take into account the final broadcast version regardless of the previous changes. 


\section{b) Literal translation (oh and variants)}

Only one instance of $o h$ is translated by means of the Catalan homograph form $o h$, as shown in (26), which clearly demonstrates that, although sharing the same written form, their usages differ considerably.

(26) Ooh. It [the yam sufflé] puffed up and everything...> Ooh... I havia pujat i tot! (Normal, Ohio)

In fact, Cuenca argues that the written from oh exists, "with different pronunciations, in English, Spanish and Catalan, where it exhibits similar expressive meanings. However, its frequency and context of use are different. English uses $o h$ more frequently than Spanish or Catalan, which implies broader contexts of use" (Cuenca 2002b: 301). Indeed, oh is among the most frequent words in the London-Lund Corpus (Aijmer 2002: 105), almost as frequent as well or as $\mathrm{mhm}$, and the third most frequent discourse particle in a study by Jucker and Smith (1998: 176). The frequency of $o h$ compared to $a h$, for example, is also remarkably higher in the British National Corpus (684 vs. 99) and in the approximate frequencies of the Longman Spoken and Written English Corpus collected by Leech et al (2001) (8,000 vs. 1,100 in British English and 8,000 vs. 300 in American English). In our English subcorpus, oh is also the most frequent interjection by far $(0.56 \%)$, especially compared to $a h(0.084 \%)$, whereas in the subcorpus of sitcoms originally broadcast in Catalan - i.e., original products, not dubbed versions - the tendency is just the opposite, $a h$ being by far the most frequent one $(0.3841 \%)$ and more rarely, oh $(0.1 \%)$.

\section{c) Translation by means of the interjection ah}

There is no doubt that if one was to attribute only one Catalan equivalent to the English interjection $o h$ with the specific meaning of "sudden realisation with no specific added value", it would be the Catalan interjection $a h$ (27). In our corpus it is the equivalent chosen in nearly $22 \%$ of all the occurrences and in $63 \%$ of the instances depicting realisation of something.

(27) Elizabeth: The line's moving counter-clockwise, Robbie.

Robbie: Huh?

Elizabeth: That's this way.

Robbie Oh. Right. Thanks.> Ah. D'acord. Gràcies. ('Oh. Right. Thanks.') (Normal, Ohio)

This is also the case for Spanish, as Chaume (2004: 849) concluded in his study of the film Pulp Fiction: "the Spanish oh shows either surprise or disappointment depending on the context. These are not the logical concepts that the English $o h$ shows [...]. The Spanish ah usually fulfils the functions of repair and questionanswer turn-taking, and both the Spanish $u h$ or $\mathrm{mmm}$ usually fulfil the function of the English $o h$ as an intensifier". 


\section{d) Translation by means of other interjections}

Finally, various interjections have been used in our corpus as translations of an original $o h$ : primary interjections such as $e i(28), a i(29), a u(30), u i(31)$, and secondary interjections such as ostres or va (32). The primary interjection $a u$ is used to denote disagreement and also compassion; $u i$ is used to articulate ironic agreement, and both $e i$ and $a i$ express pleasure.

(28) Ooh, do that again, do that again, do that again $>E i$, torna-hi, torna-hi! (Working)

(29) $O h$ ! I'm just feeling so ridiculously horny.> $A i$, em sento ridículament calenta! (Coupling)

(30) Oh, Bill, there's no such thing as bad luck.> $A u$, Bill, això no és cosa de la mala sort. (Working)

(31) Oh, I'm sure they love it!>Ui, n'estan enamorats! (Working)

These are not the first equivalents that would spring to the mind of a native speaker but, as stated before, versatility is one of the features of primary interjections whose meaning easily changes thanks to intonation, allowing one interjection to accomplish different functions. As far as secondary interjections are concerned, $v a$ ('come on') is used in two instances where $o h$ reinforces a conative meaning (see 19 above), evident from the context and the cotext. On the other hand, ostres (literally, 'oysters') is used to manifest pain, as shown in (32). In both cases the translator has chosen an interjection with the same meaning as the original but with a totally different form.

(32) Oh! My hands! Watch out!> Ostres! Que em cremo les mans! (Normal, Ohio)

Figure 4 summarises the information taking into account the meaning of the interjection.

\subsection{Translation strategies of oh in combinations}

Focussing on the occurrences where the interjection oh is either repeated or combined with other interjections, further conclusions can be drawn regarding their translation strategies. As for the repetition of $o h$, the strategies ascertained are either a reduction or a repetition: in two occasions the interjection is reduced to a single interjection ("oh, $o h, o h>a h$ "), whereas there is one case depicting pleasure in which the duplication is kept ("oh, oh> $a h, a h$ "). In all cases the translation chosen is the interjection $a h$, which conveys the same meaning with a dissimilar form. On the other hand, regarding the combinations of $o h$ with other interjections, ${ }^{3}$ two

3. Matamala and Lorente (forthcoming) present an analysis of the different combinations in which various interjections occur. 


\begin{tabular}{|c|c|c|c|c|c|c|}
\hline & & & Omission & $\begin{array}{l}\text { Ah } \text { and } \\
\text { variants }\end{array}$ & $\begin{array}{l}\text { Oh and } \\
\text { variants }\end{array}$ & Interj \\
\hline \multirow[b]{2}{*}{ Expressive } & Pleasure & 4 & 2 & 0 & 0 & $\mathrm{Ei}$, ai \\
\hline & Pain & 1 & 0 & 0 & 0 & Ostres \\
\hline Realisation & +no specific value & 11 & 4 & 7 & 0 & 0 \\
\hline \multirow[t]{6}{*}{ Realisation } & + disappointment & 1 & 0 & 0 & Ooh & 0 \\
\hline & +complaint/moan & 2 & 2 & 0 & 0 & 0 \\
\hline & +surprise & 5 & 5 & 0 & 0 & 0 \\
\hline & + pity & 1 & 0 & 0 & 0 & $\mathrm{Au}$ \\
\hline & +admiration & 3 & 1 & 2 & 0 & 0 \\
\hline & +annoyance & 1 & 1 & 0 & 0 & 0 \\
\hline \multirow[t]{5}{*}{ Realisation } & +phatic/agreement & 6 & 5 & 0 & 0 & Ui \\
\hline & +phatic/disagreement & 1 & 0 & 0 & 0 & $\mathrm{Au}$ \\
\hline & +conative/incite sb to do sth & 5 & 3 & 0 & 0 & $\mathrm{Va}(2)$ \\
\hline & & 41 & 23 & 9 & 1 & 8 \\
\hline & & & $56.1 \%$ & $21.95 \%$ & $2.44 \%$ & $19.51 \%$ \\
\hline
\end{tabular}

Figure 4. Translation strategies.

main strategies are observed: omission of an interjection and translation by other interjections, along with other minor variants described next.

\section{a) Omission of an interjection}

In two instances the primary interjection is omitted and only the secondary interjection translated (33), whereas in just one case the secondary interjection is obviated (34) and in another instance a primary interjection plus a secondary interjection are eliminated (35), leaving only the translation of "please" in the target language version.

(33) Oh God > Senyor ('Lord!') (Coupling)

Oh look, I'm sorry I'm late.> Daixò, em sap greu arribar tard. ('Look, I'm sorry I'm late') (Coupling)

(34) Oh, darn. I'm out of popcorn.> Ah! Se m'han acabat les crispetes. ('Oh! I'm out of popcorn') (Normal, Ohio) 
(35) Oh, God, please don't tell me you have a plan> Sisplau, no em diguis que tens un pla...('Please, don't tell me you have a plan') (Working)

Although it could seem that the intensity is not the same (see the first example), in Catalan the usage of an oh before Senyor is not as frequent as in English and could be easily regarded as a calque, the proposed translation being the most appropriate one. On the other hand, dubbing also allows the omission of the interjection and the inclusion of vocal sounds which are not proper interjections and which are represented by the symbol "(G)", meaning "vocal gesture". This is why "Oh, thank you" becomes " $(\mathrm{G})$ Gràcies" (i.e., a non-linguistic sound plus the literal translation of the interjection 'thank you') in the sitcom Normal, Ohio.

\section{b) Translation of all interjections by means of other interjections}

Finally, in two instances, the interjection $o h$ is translated by means of another interjection with a different form $(o h>a h)(36)$, whereas one opts for a literal translation (37).

(36) Oh, hello, Butch.> Ah, hola, Butch. (Normal, Ohio)

Oh, sure, yeah, absolutely> Oh, sí, sí, esclar. (Coupling)

The second example is particularly interesting because it reflects an improvisation by the dubbing actor. In fact, the translator had written "Ah, sí, sí, esclar" ('Oh, yes, yes, of course'), a proposal maintained by the adaptor -in charge of lip-synch — and the linguist — who revises the linguistic quality of the text—, but in the recording stage of the dubbing process the actor changed the interjection $a h$ and said $o h$, a less appropriate option taking into account the frequency of these units in the source and target language, as already pointed out in previous studies.

Figure 5 summarises all the translation strategies concerning repetitions and combinations in which $o h$ is present.

Focussing exclusively on the translation of $o h$ in combinations and repetitions -and considering the two instances of reductions as occurrences of both omission and translation by the interjection $a h-$, the resulting percentages can be applied to the translation strategies established in section 4.1 (Figure 6).

A review of the results of translating $o h$ when it is followed by other linguistic units (Figure 4) and in the few examples when is found in combinations (Figure 6), allows one to conclude that omission is the main strategy in Catalan, this is especially true for the former group. The translation of $o h$ by means of $a h$ is also a frequent strategy, although used much more commonly for combinations, whereas literal translations of $o h$ are generally avoided in our corpus. The most significant difference is the translation of $o h$ by means of various interjections in noncombined interjections: this occurs in $19.51 \%$ of cases and is not used as a strategy at all in the other group.

The data presented in this section coincide approximately with Cuenca's analysis (2004: 13) of the movie Four Weddings and a Funeral, who identifies six strate- 


\begin{tabular}{|l|l|l|l|}
\hline Repetitions & & Original & Translation \\
\hline Reduction & $\begin{array}{l}\text { Oh, oh, oh + sentence- } \\
\text { equivalent item } \\
\text { Oh, oh, oh + sentence }\end{array}$ & $\begin{array}{l}\text { Ah + sentence-equivalent } \\
\text { item } \\
\text { Ah + sentence }\end{array}$ \\
\hline Repetition & Oh, oh + vocative & Ah, ah + vocative \\
\hline Combinations & ...primary interjection & $\begin{array}{l}\text { Oh God } \\
\text { Oh, look }\end{array}$ & $\begin{array}{l}\text { Senyor! } \\
\text { Daixò }\end{array}$ \\
\hline Omission of the... & ...secondary interjection & Oh, darn & Ah! \\
\cline { 2 - 4 } & $\ldots$ primary + secondary & Oh, God, please & Sisplau \\
\hline Oh $>(\mathrm{G})$ & Oh, thank you & (G) Gràcies \\
\hline Oh $>$ Ah & $\begin{array}{l}\text { Oh, hello } \\
\text { Oh, right, thanks }\end{array}$ & $\begin{array}{l}\text { Ah, hola } \\
\text { Ah, d'acord, gràcies }\end{array}$ \\
\hline Oh $>$ Oh & Oh, sure & Oh, sí \\
\hline
\end{tabular}

Figure 5. Translation strategies in combinations and repetitions.

\begin{tabular}{|l|l|l|}
\hline Omission & 6 & $46.15 \%$ \\
\hline Oh $>$ Ah & 6 & $46.15 \%$ \\
\hline Literal translation $(\mathrm{oh}>\mathrm{oh})$ & 1 & $7.7 \%$ \\
\hline
\end{tabular}

Figure 6. Translations strategies of $o h$ in combinations.

gies $^{4}$ when translating interjections into Spanish and Catalan and concludes that, while primary interjections are literally translated or omitted in Spanish, in Catalan they are generally omitted or translated by means of interjections with dissimilar forms but the same meaning. As for combinations, Spanish translators usually choose a literal translation or omit the combination, whereas in Catalan using a combination with a dissimilar form but the same meaning or omitting the interjections are again the most common strategies.

Chaume (2004) also analyses the translation from English into Spanish of various discourse markers in three different versions of the movie Pulp Fiction -written translation, dubbed version and subtitled version-, and concludes that from the sixteen units found in the source text, thirteen appear in the written trans-

4. The six strategies (based on Baker's proposal) are: literal translation (strategy a); translation by using an interjection with dissimilar form but the same meaning (strategy b); translation by using a non-interjective structure with similar meaning (strategy c); translation by using an interjection with a different meaning (strategy d); omission (strategy e); addition of elements (strategy f). 
lation (81\%), eleven finally find their way in the dubbed version (68\%) and only one in the subtitled version (6\%). Although Chaume states that the lack of discourse markers could make audiovisual translations less cohesioned texts, the audience can repair the possible misunderstandings thanks to their linguistic and textual competence, to the presence of the visual text which makes audiovisual texts often redundant, and also thanks to their knowledge of the genre of audiovisual translation. As far as translation strategies in the dubbed version are concerned, literal translation is used in more than 50\% of the cases (6 occurrences), whereas the rest correspond to various interjections ( 3 instances of $\mathrm{mmm}, 1$ of $a \mathrm{~h}$ and 1 of $u h$ ). The comparison of this data with the data from my previous analysis reinforces the idea that Spanish translations tend to be more literal than Catalan translations, which opt for more dynamic translations which imitate more faithfully real spontaneous oral language (cf. also Cuenca 2006). ${ }^{5}$

\section{Conclusions}

In conclusion, this article has hopefully shed some light on the usage of the interjection $o h$ in English and its translation in Catalan. Taking into account a corpus of sitcoms, different functions have been identified and some remarks have been made concerning their position and their combination with other units. On the other hand, the translation of the interjection oh - both alone and in combinations- in a corpus of dubbed sitcoms has been described and, despite the presence of a homograph form in Catalan, it has been demonstrated that omission is the main strategy, along with translation by means of other interjections with dissimilar forms (especially $a h$ ), strategies which do not generally affect meaning and which respond to the differentiated behaviour of these units in both languages. Dubbing constraints have also been taken into account, as well as frequency issues. All in all, this article has demonstrated that, even though two languages can share a same written form, their usages differ and good translations such as those analysed should bear this in mind.

\section{References}

Aijmer, Karin (2002). English Discourse Particles: Evidence from a Corpus. Amsterdam/Philadelphia: John Benjamins. Studies in Corpus Linguistics, 10.

Bazzanella, Carla; Morra, Lucia (2000). "Discourse markers and the indeterminacy of translation”. In: Korzen, Iorn; Marello, Carla (eds.). Argomenti per una lingüística della traduzione. Alessandria: Edizione dell'Orso, pp. 149-157.

Briz, Antonio (2001). El español coloquial en la conversación. Barcelona: Ariel.

5. There is no doubt that a further study on the style of conversation in English vs. the style of conversation in Catalan and Spanish could be very useful, but it goes beyond the objective of this article. Matamala (2005b) analyses the orality of a corpus of sitcoms (both dubbed into Catalan and originally written in Catalan) in comparison with spontaneous language focussing on the usage of interjections and could be considered a starting point. 
Chaume, Frederic (2004). "Discourse markers in audiovisual translating". Meta 49 (4): 843-855.

Cuenca, M. Josep (2000). "Defining the indefinable? Interjections". Syntaxis 3: 29-44. Cuenca, M. Josep (2002a). "Els connectors textuals i les interjeccions". In: Solà, Joan et al (coord.). Gramàtica del Català Contemporani. Barcelona: Empúries, pp. 3173-3237.

Cuenca, M. Josep (2002b). "Translating interjections for dubbing”. Studies in Contrastive Linguistics. Proceedings of the 2nd International Contrastive Linguistics Conference. Santiago de Compostela: Servicio de Publicacións e Intercambio Científico, Universidade de Santiago de Compostela, pp. 299-310.

Cuenca, M. Josep (2004). "Translating interjections: an approach from grammaticalization theory". In: Soares da Silva, Augusto; Torres, Amadeu; Gonçalves, Miguel (eds.). Linguagem, Cultura e Cognição: Estudos de Linguística Cognitiva. Coimbra: Almedina, vol. 2, pp. 325-345.

Cuenca, M. Josep (2006). "Interjections and pragmatic errors in dubbing". Meta 51 (1): 20-35.

Fischer, Kerstin (2000). From Cognitive Semantics to Lexical Pragmatics. The Functional Polysemy of Discourse Particles. Berlin: Mouton de Gruyter.

Heritage, John (1984). "A change-of-state token and aspects of its sequential placement." In: Atkinson, J. Maxwell; Heritage, John (eds.). Structures of Social Action. Studies in Conversation Analysis. Cambridge: Cambridge University Press, pp. 199-345.

Hernanz, Maria-Lluïsa (2002). "L'oració". In: Solà, Joan et al (coord.). Gramàtica del Català Contemporani. Barcelona: Empúries, pp. 993-1073.

James, Deborah (1973). The Syntax and Semantics of Some English Interjections. University of Michigan, doctoral dissertation.

Jucker, Andreas H.; Smith, Sara W. (1998). "And people just you know like "wow"”. In: Jucker, Andreas H.; Ziv, Yael (eds.). Discourse Markers: Descriptions and Theory. Amsterdam/ Philadelphia: John Benjamins.

Leech, Geoffrey; Rayson, Paul; Wilson, Andrew (2001). Word Frequencies in Written and Spoken English: Based on the British National Corpus. London: Longman.

Matamala, Anna (2005a). Les interjeccions en un corpus audiovisual. Descripció $i$ representació lexicogràfica. Barcelona: Universitat Pompeu Fabra, IULA. Sèrie Tesis 14.

Matamala, Anna (2005b). "Converses espontànies o converses prefabricades? Les interjeccions en comèdies de situació catalanes i doblades". Estudios Catalanes. Revista Internacional de Lengua, Literatura y Cultura Catalanas 3: 65-77.

Matamala, Anna (forthcoming). "Interjections in original and dubbed sitcoms: a comparison". Meta. Journal des traducteurs. Montreal: Presses Universitaires.

Matamala, Anna; Lorente, Mercè (forthcoming). "Combinatòria d'interjeccions i llengua oral". Actes del XIIIè Col-loqui Internacional de Llengua i Literatura Catalanes (Girona, 9 de setembre, 2003). Barcelona: Publicacions de l'Abadia de Montserrat.

Schiffrin, Deborah (1987). Discourse Markers. Cambridge: Cambridge University Press.

Schourup, Lawrence (1985). Common Discourse Particles in English Conversation. Ohio: Ohio State University.

Tannen, Deborah; Lakoff, Robin (1994). Gender and Discourse. Oxford: Oxford University Press. 
Torres Vilatarsana, Marta (1999). Les interjeccions: aproximació pragmàtica a partir de converses presencials i virtuals. Universitat de Barcelona. Unpublished Degree's Dissertation.

Tshomba, Lombela-Poyo (1986). "The role of interjections in discourse". Estudios de Lingüística Aplicada 6: 42-64. 